\title{
Heat and Mass Transfer past a Continuously Moving Porous Boundary in the Presence of a Magnetic Field
}

\author{
M. N. Raja Shekar \\ Associate Professor \& Head \\ Department of Mathematics \\ JNTUH College of Engineering \\ Nachupally (Kondagattu) \\ Karimnagar
}

\author{
S. Karunakar Reddy \\ Department of Mathematics \\ JNTUH College of Engineering \\ Kukatpally, Hyderabad
}

\begin{abstract}
The effect of magnetic field on the flow and heat and mass transfer processes when the fluid flows past a continuously moving porous plate has been analyzed. The governing boundary layer equations have been reduced to a set of nonlinear ordinary differential equations using similarity transformations. The governing equations are solved using an implicit finite-difference scheme of Crank-Nicolson type. The effects of magnetic and suction (or injection) parameters on the velocity, temperature and concentration profiles as well as on the heat transfer coefficient have been studied numerically and are shown in figures. Numerical computations have been carried out for different values of $f_{w} g_{s}$ and $g_{c}$ and for fixed values of $S c$.
\end{abstract}

\section{keywords}

Heat transfer, Mass Transfer, Magnetic field

\section{INTRODUCTION}

Modern technology and natural world around us, we always encounter transport processes where in motion is derived simply in a gravitational field. The phenomenon of free convection arises in a fluid when temperature changes cause density variation leading to buoyancy forces acting on the fluid elements. Circumstances occur wherein buoyancy forces arise due to difference in salinity. One of the exact solutions of the Navier-Stokes equation which exists for the flow due to an impulsive start of an infinite plate, was first studied by Stokes ${ }^{1}$. This problem is also known in the literature as Rayleigh's problem.

In the present paper, we have studied the effect of magnetic field on the flow and heat and mass transfer processes when the fluid flows past a continuously moving porous boundary. The porous diffusion associated with such problems and their special cases find applications in manufacturing processes in industries as well as in the subsoil flows of water and hydrocarbons. In fact, this problem is a generalization of the corresponding problem of hydro-magnetic flow over a flat plate. Some of the earlier studies in this direction are those of Soundalgekar ${ }^{2}$ studied the flow of a viscous incompressible fluid past an infinite vertical impulsively started thermal plate taking into account the presence of free-convection currents.. Soundalgekar ${ }^{3}$ also studied the effects of mass transfer of the flow past an infinite vertical impulsively started plate.

The problem of free-convection flow of an electrically conducting fluid, past a vertical plate, under the influence of a magnetic field attracted many researchers because of its applications in technological field. Gokhale and
Soundalgekar ${ }^{4}$ studied the effect of a transversely applied magnetic field on the transient free-convective flow of an electrically conducting fluid past a semi-infinite vertical plate with constant heat flux. The effects of mass transfer on the flow of an incompressible viscous fluid past an impulsively started infinite vertical plate in case of variable temperature and constant heat flux were recently studied by Soundalgekar, et. $a{ }^{5} .^{5}$ Cobble $^{6}$ discussed the hydro-magnetic flow over a semi-infinite plate in the presence of a transverse magnetic field and a pressure gradient with or without injection or suction and obtained similarity solutions for these. The heat transfer characteristics of this problem have been studied by Soundalgekar, et.al. ${ }^{7}$ and Singh $^{8}$. The effects of mass transfer on the MHD flow of an incompressible viscous fluid past an impulsively started infinite vertical plate, subjected to a variable temperature and constant heat flux, was studied by Shanker, et.al. ${ }^{9}$. Elbashbeshy ${ }^{10}$ studied heat and mass transfer along a vertical plate with variable surface temperature and concentration in the presence of magnetic field. Muthucumaraswamy and Senthil ${ }^{11}$ investigated the heat and mass transfer effect on moving vertical plate in the presence of thermal radiation. Ishaket.al ${ }^{12}$ studied on MHD stagnation point flow towards a stretching vertical sheet in a micro-polar fluid. Unsteady MHD Heat and Mass transfer flow of chemically reacting fluid past an impulsively started vertical plate, was studied by Raja Shekaret.al. ${ }^{13}$. In this study, we have extended the above analyses to the flow past a continuously moving semi-infinite porous plate. The governing boundary layer equations have been transformed to a two-point boundary value problem in similarity variables, and these have been solved numerically. The effects of magnetic field and the porous boundary on the flow and heat transfer have been shown graphically for some fluids.

\section{EQUATIONS}

Consider the two-dimensional flow of a viscous, incompressible and electrically conducting fluid past a continuously moving semi-infinite porous plate under the influence of a transversely applied magnetic field. As the conductivity and hence the magnetic Reynolds number is very small for most fluids used in industrial applications, we assume that the induced magnetic field is negligible in comparison with the applied one. It is also assumed that the external electric field and the electric field due to polarization of charges are negligible. This assumption corresponds to the case when no energy is added to or extracted from the fluid by the electric field. 
Let the $\mathrm{x}$-axis be taken along the direction of the moving plate and y-axis normal to it. If $u$ and $v$ are the velocity components along these directions, respectively, then under the usual boundary layer approximation, the hydro-magnetic steady flow and heat and mass transfer for the present problem are governed by the equations

$\frac{\partial u}{\partial x}+\frac{\partial v}{\partial y}=0$

$\frac{\partial u}{\partial x}+v \frac{\partial v}{\partial y}=v \frac{\partial^{2} v}{\partial y^{2}}+g \beta\left(T-T_{\infty}\right)+g \beta^{*}\left(C-C_{\infty}\right)$

$-\frac{\sigma B_{0}^{2} u}{\rho}$

$u \frac{\partial T}{\partial x}+v \frac{\partial T}{\partial y}=\alpha \frac{\partial^{2} T}{\partial y^{2}}$

$u \frac{\partial C}{\partial x}+v \frac{\partial C}{\partial y}=D \frac{\partial^{2} C}{\partial y^{2}}$

Here $\rho$ is the fluid density, $v$ the kinematic viscosity, $\sigma$ the electrical conductivity, $B_{0}$ the magnetic field strength, $\alpha$ the thermal diffusivity, $T$ the temperature of the fluid, $C$ the concentration of the fluid, $g$ the gravitational acceleration, $\left(\beta, \beta^{*}\right)$ are the temperature and concentration coefficients of volumetric expansion.

Equations (1) - (4) are solved subject to the following boundary conditions

$$
\left.\begin{array}{c}
u=U, v=-V(x), T=T_{w}, C=C_{w}, \quad \text { at } \quad y=0 \\
u \rightarrow 0, T \rightarrow T_{\infty}, C \rightarrow C_{\infty}, \quad \text { at } y \rightarrow \infty
\end{array}\right\}
$$

We now introduce the following dimensionless variables

$$
\begin{aligned}
& \eta=y \sqrt{\frac{U}{2 v x}}, u=U f^{\prime}(\eta), v=\sqrt{v U / 2 x}\left(\eta f^{\prime}(\eta)-f(\eta)\right), \\
& M=\frac{2 \sigma B_{0}^{2} x}{\rho U}, f_{w}=-V(x) \sqrt{2 x / v U}, \theta(\eta)=\frac{T-T_{\infty}}{T_{w}-T_{\infty}} \\
& \phi(\eta)=\frac{C-C_{\infty}}{C_{w}-C_{\infty}}, \operatorname{Pr}=\frac{v}{\alpha}
\end{aligned}
$$

Using the above transformations in equations (2) - (4), the boundary layer equations become

$$
\begin{aligned}
& f^{\prime \prime \prime}+f f^{\prime \prime}+g_{s} \theta+g_{c} \phi-M f^{\prime}=0 \\
& \theta^{\prime \prime}+\operatorname{Pr} f \theta^{\prime}=0 \\
& \phi^{\prime \prime}+S c f \phi^{\prime}=0
\end{aligned}
$$

The prime values denote the differentiation with respect to $\eta$.

The boundary conditions in the new variables form are:

$$
\left.\begin{array}{c}
f=f_{w}, f^{\prime}=1, \theta=1, \phi=1 \quad \text { at } \quad \eta=0 \\
f^{\prime}=0, \quad \theta=0, \quad \phi=0 \quad \text { as } \eta \rightarrow \infty
\end{array}\right\}
$$

In order to facilitate the application of finite difference scheme, one has to transform the equations (7) - (9) to a new system of coordinates wherein the infinite limit of integration in $\eta$ replaced by a finite limit.

Employing the transformation

$$
\mathrm{Z}=1-\mathrm{e}^{-\mathrm{c} \eta}, \mathrm{Q}=c(1-\mathrm{Z})
$$

where $c$ is a constant that can be used as a scaling factor to provide an optimum distribution at nodal points. The above equation reduces to

$$
\begin{aligned}
& \mathrm{Q}^{3} f^{\prime \prime \prime}+\mathrm{Q}^{2} f f^{\prime \prime}+\mathrm{g}_{\mathrm{s}} \theta+\mathrm{g}_{\mathrm{c}} \phi-M \mathrm{Q} f^{\prime}=0 \\
& \mathrm{Q}^{2} \theta^{\prime \prime}+\mathrm{Q} \operatorname{Pr} f \theta^{\prime}=0 \\
& \mathrm{Q}^{2} \phi^{\prime \prime}+\mathrm{Q} S c f \phi^{\prime}=0
\end{aligned}
$$

The boundary conditions reduces to

$$
\left.\begin{array}{c}
\mathrm{Z}=0, f=f_{w}, f^{\prime}=\frac{1}{c}, \theta=\phi=1 \\
\mathrm{Z}=1, \quad f^{\prime}=0, \quad \theta=\phi=0
\end{array}\right\}
$$

The Quasi-linearization (Bellman et al. ${ }^{14}$ ) of all nonlinear terms in equation (11) it yields

$\mathrm{Q}^{3} f^{\prime \prime \prime}+\mathrm{Q}^{2}\left(F f^{\prime \prime}+f F^{\prime \prime}\right)-M \mathrm{Q} f^{\prime}=\mathrm{Q} F F^{\prime \prime}-\mathrm{g}_{\mathrm{s}} \theta-\mathrm{g}_{\mathrm{c}} \phi$

where $\mathrm{F}$ and $\mathrm{F}^{\prime}$ are assumed to be known. A Gaussian elimination process is used to solve equation (15) numerically. The numerical solution of $f$ after i-repeated Gaussian elimination processes are considered as the $\mathrm{i}^{\text {th }}$ order iterative solution, while $\mathrm{F}$ and $\mathrm{F}^{\prime}$ are the $(\mathrm{i}-1)^{\text {th }}$ order solutions. If a convergence can be reached i.e. $|f-F| \rightarrow 0$ for all $\mathrm{Z}$ then $f$ converges to the solution of equation (15).

\section{SOLUTION OF THE PROBLEM}

The interval 0 to 1 in Z-direction is divided into 10 equal subintervals each of length $h=1 / 10$. The governing equations (11) - (13) are discritized to corresponding finite difference equations by employing the following difference quotients and are solved by using the Thomas algorith ${ }^{15}$ or by a very efficient algorithm due to Evans ${ }^{16}$.

$$
\begin{aligned}
& f_{i}^{\prime}=\left(f_{i+1}-f_{i-1}\right) / 2 \mathrm{~h}, \\
& f_{i}^{\prime \prime}=\left(f_{i+1}-2 f_{i}+f_{i-1}\right) / \mathrm{h}^{2}, \\
& f_{i}^{\prime \prime \prime}=\left(-f_{i-2}+2 f_{i-1}-2 f_{i+1}+f_{i+2}\right) / 2 \mathrm{~h}^{3}
\end{aligned}
$$

Thus, the finite difference equations corresponding to equations (12), (13) and (15) are

$$
\begin{aligned}
& \mathrm{A} 1(\mathrm{i}) \theta_{\mathrm{i}-1}+\mathrm{A} 2(\mathrm{i}) \theta_{\mathrm{i}}+\mathrm{A} 3(\mathrm{i}) \theta_{\mathrm{i}+1}=0 \\
& \mathrm{~B} 1(\mathrm{i}) \phi_{\mathrm{i}-1}+\mathrm{B} 2(\mathrm{i}) \phi_{\mathrm{i}}+\mathrm{B} 3(\mathrm{i}) \phi_{\mathrm{i}+1}=0 \\
& \mathrm{C} 1(\mathrm{i}) f_{\mathrm{i}-2}+\mathrm{C} 2(\mathrm{i}) f_{\mathrm{i}-1}+\mathrm{C} 3(\mathrm{i}) f_{\mathrm{i}}+\mathrm{C} 4(\mathrm{i}) f_{\mathrm{i}+1}+\mathrm{C} 5(\mathrm{i}) f_{\mathrm{i}+2}=0
\end{aligned}
$$

Where

$$
\begin{aligned}
& \mathrm{Q}(\mathrm{i})=c(1-\mathrm{i} h), \mathrm{C} 1(\mathrm{i})=-\mathrm{Q}(\mathrm{i})^{3}, \mathrm{D}(\mathrm{i})=2 \mathrm{Q}(\mathrm{i})^{3}+\mathrm{MQ}(\mathrm{i}) h^{2}, \\
& \mathrm{C} 2(\mathrm{i})=\mathrm{D} 1(\mathrm{i})+2 h \mathrm{Q}(\mathrm{i})^{2} \mathrm{~F}(\mathrm{i}), \mathrm{C} 4(\mathrm{i})=-\mathrm{D} 1(\mathrm{i})+2 h \mathrm{Q}(\mathrm{i})^{2} \mathrm{~F}(\mathrm{i}), \\
& \mathrm{C} 3(\mathrm{i})=-2 \mathrm{Q}(\mathrm{i})^{2} \mathrm{~F}(\mathrm{i})+2 h^{3} \mathrm{Q}(\mathrm{i})^{2} \mathrm{~F}^{\prime \prime}(\mathrm{i}), \mathrm{C} 5(\mathrm{i})=-\mathrm{C} 1(\mathrm{i}) \\
& \mathrm{C} 6(\mathrm{i})=2 h^{3}\left[\mathrm{QFF}^{\prime \prime}-\mathrm{g}_{\mathrm{s}} \theta(\mathrm{i})-\mathrm{g}_{\mathrm{c}} \phi(\mathrm{i})\right],
\end{aligned}
$$




$$
\begin{aligned}
& \mathrm{A} 1(\mathrm{i})=2 \mathrm{Q}(\mathrm{i})^{2}-h \operatorname{PrQ}(\mathrm{i}) \mathrm{F}(\mathrm{i}), \mathrm{A} 2(\mathrm{i})=-4 \mathrm{Q}(\mathrm{i})^{2}, \\
& \mathrm{~A} 3(\mathrm{i})=2 \mathrm{Q}(\mathrm{i})^{2}+h \operatorname{PrQ}(\mathrm{i}) \mathrm{F}(\mathrm{i}), \mathrm{B} 1(\mathrm{i})=2 \mathrm{Q}(\mathrm{i})^{2}-h S c \mathrm{Q}(\mathrm{i}) \mathrm{F}(\mathrm{i}), \\
& \mathrm{B} 2(\mathrm{i})=-4 \mathrm{Q}(\mathrm{i})^{2}, \mathrm{~B} 3(\mathrm{i})=2 \mathrm{Q}(\mathrm{i})^{2}+h S c \mathrm{Q}(\mathrm{i}) \mathrm{F}(\mathrm{i}) .
\end{aligned}
$$

\section{RESULTS AND DISCUSSION}

Numerical computations have been carried out for different values of $f_{w}, g_{s}$ and $g_{c}$ and for fixed values of $S c$. The value of Prandtl number Pr is taken equal to 0.71 which corresponds physical to air. The value of Schmidt number $S c=0.22$ have been chosen to represent hydrogen $T_{m}=25^{\circ} \mathrm{C}$ and $1 \mathrm{~atm}$. The numerical results for the velocity, temperature and concentration profiles are shown in Figs. 1-4. In Fig.1, velocity profiles are shown for different values of $g_{s}$ and $g_{c}$ parameters. It is seen from this figure that the velocity profiles increases with the increase of $g_{s}$ parameter. The variation of temperature and concentration fields for different values of $g_{s}$ and $g_{c}$ are displayed in Fig.2 and Fig. 3 respectively. As would be expected, both fields exhibit the same behavior. The influence of $g_{c}$ parameter on the temperature and concentration field is not so much evident for higher values of $g_{s}$ parameter.

\section{SKIN-FRICTION}

The physical quantities of most interest in such problems is the skin-friction coefficient $\left(C_{f}\right)$ and is given by

$C_{f}=\frac{2 \tau_{w}}{\rho U_{\infty}^{2}}, \tau_{w}=\left[\mu \frac{\partial u}{\partial y}\right]_{y=0}$ is the rate of heat transfer

From the process of numerical computation, the above coefficients sorted out in the form of Table for $\operatorname{Pr}=0.71$, Sc $=0.22, g_{s}=1.0$ and $g_{c}=0.05$ as given below.

\begin{tabular}{|c|c|c|}
\hline$M$ & $S c$ & $C_{f}$ \\
\hline 0.02 & 2.00 & 1.4222 \\
0.06 & 2.00 & 1.3671 \\
0.10 & 2.00 & 1.3069 \\
0.02 & 2.00 & 1.4222 \\
0.02 & 0.40 & 1.4260 \\
0.02 & 0.10 & 1.4650 \\
\hline
\end{tabular}

\section{CONCLUSIONS}

In this paper, effects of Magnetic field on the flow and heat and mass transfer processes when the fluid flows past a continuously moving porous boundary has been studied theoretically. From the present study we see that the momentum boundary layer thickness decreases with an decrease of $g_{s}$ and increases with an increase of $g_{c}$ parameter, whereas both the thermal and species concentration boundary layer thickness increase with an decrease of $g_{s}$ and decrease with an increase of $g_{c}$ parameter. Therefore, we conclude that effect of magnetic field on the flow should be neglected.

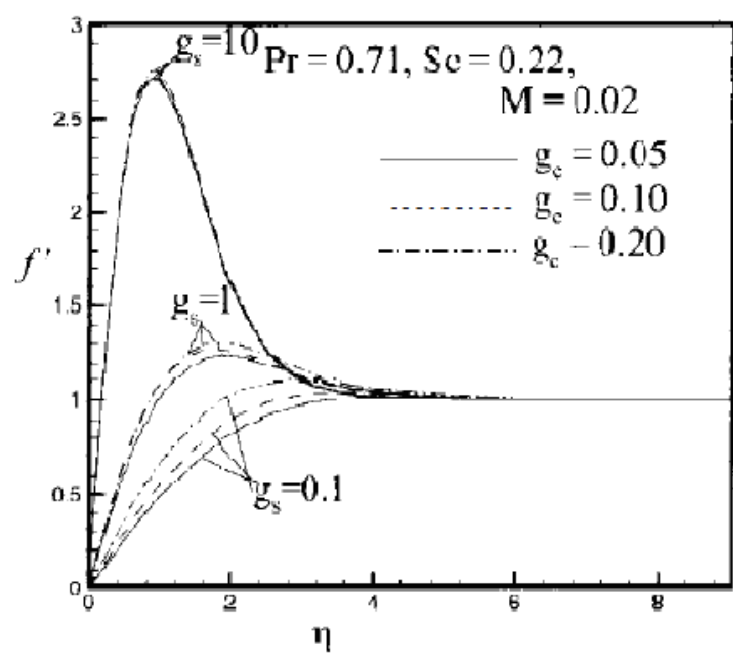

Fig. 1 : Velocity Profiles for difference values of gs and gc.

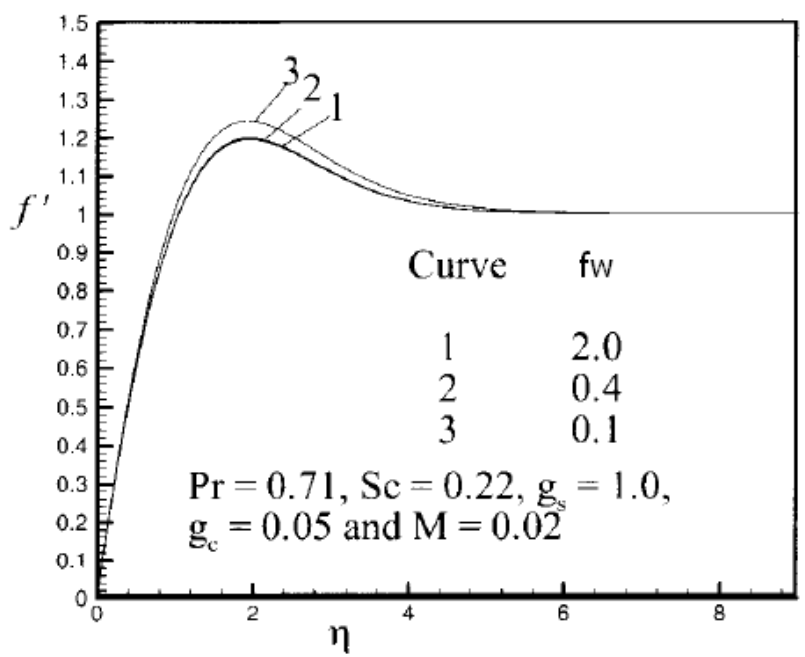

Fig.2 : Velocity Profiles for different values of $\mathrm{fw}$.

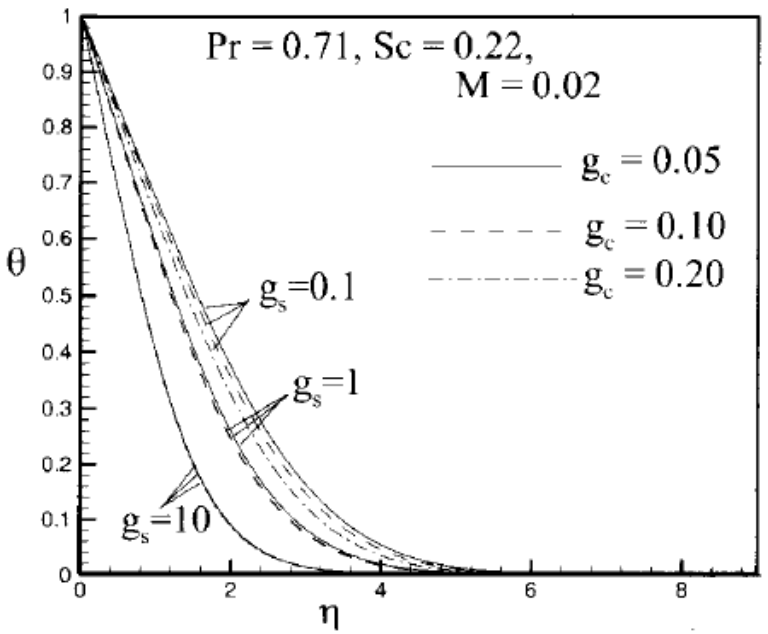

Fig. 3 : Temperature Profiles for different values of gs and gc. 


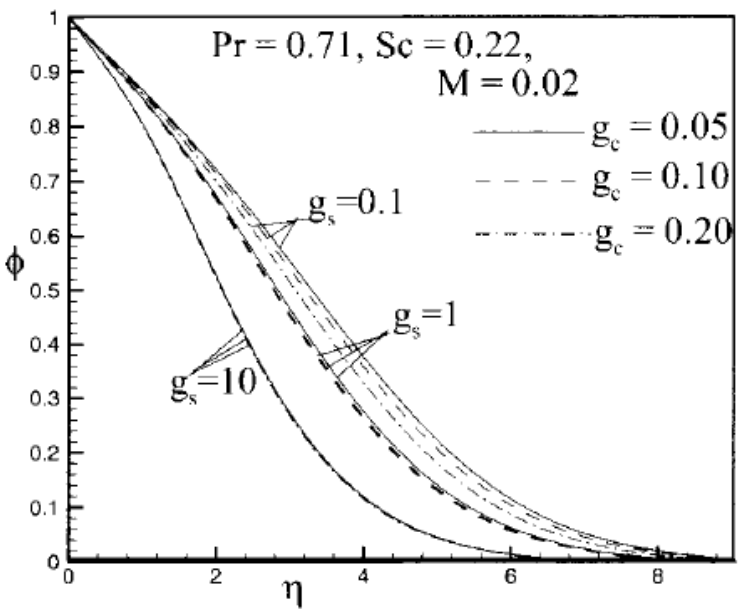

Fig. 4: Concentration Profiles for different values of gs and gc

\section{REFERENCES}

[1] Stokes, G. G. : 1851, Camb. Phi. Soc. Trans.,Vol.9, 8

[2] Soundalgekar, V. M. : 1977, Journal of Heat Transfer, Trans. of ASME, Vol.99, 499.

[3] Soundalgekar, V. M. : 1979, Journal of Applied Mechanics, Trans. of ASME, Vol.46, 757.

[4] Gokhale, M. R. and Soundalgekar, V. M. : 1991, Canadian Journal of Physics, Vol. 69, 1451.
[5] Soundalgekar, V. M., Birakdar, N. S. and Darwhekar, V. K. : 1980, Astrophysics and Space Science, Vol.100, 159.

[6] Cobble, M. H.: 1977, J. Engg. Math., Vol.11, 249.

[7] Soundalgekar, V. M. and Murthy, T. V. R.: 1980, J. Engg. Math. Vol.14, 155.

[8] Singh, A. K. : 1985, Astrophys. Space Sci., Vol.115, 387.

[9] Shanker, B. and Kishan, N. : 1997, Journal of Energy, Heat and Mass Transfer, Vol19, 273.

[10] Elbashbeshy, E. M. A. : 1997, Int. J. Engg. Sci., Vol. 34, 515 .

[11] Muthucumaraswamy R. and Senthil Kumar G. : 2004, Theoretical Applied Mechanics, Vol.31, 35.

[12] Ishak, A., Nazar, R. and Pop I.: 2007 Magnetohydrodynamics, Vol. 43, 83.

[13] Raja Shekar, M. N. and VenkatMadhu, J. : 2011, International Journal of Computer Applications in Engineering, Technology and Science s, Vol.4, 37.

[14] Bellman, R. E. and Kalaba, R. E. : 1965, QuasiLinearization and Non-Linear Boundary Value Problems, Elsevier, New York.

[15] Thomas, L. H. : 1949, Walson Scientific Computing Lab. Columbia Univeristy, New York.

[16] Evans, D. J.: 1972, Computer Journal, Vol.15, 1356. 